\title{
Serum Free Amino Acid Depletion in Ketotic Children
}

\author{
Masaki HAYASHI, ${ }^{1}$ Kazutaka KonISHI, ${ }^{2}$ Akio KAMEOKA, ${ }^{2}$ \\ and Makoto MINO \\ ${ }^{1}$ Department of Pediatrics, Osaka Rosai Hospital, \\ Sakai 571, Japan \\ ${ }^{2}$ Department of Pediatrics, Osaka Medical College, \\ Takatsuki 569, Japan \\ (Received July 7, 1981)
}

\begin{abstract}
Summary Changes in serum free amino acids as a response to ketogenic provocative test were studied in children with a history of ketosis but without hypoglycemia.

1. Of the 17 children who underwent the provocative test, only three showed clinical manifestations. They were among five children who responded to the test and developed hypoglycemia.

2. Hypoglycemic and non-hypoglycemic children differed greatly in the decrement of serum total gluconeogenic amino acids after completion of the test due to the relatively lower levels before provocation in the hypoglycemic group and the inversely higher levels in the nonhypoglycemic group.

3. Gluconeogenic amino acids that decreased sharply after the test were glycine, alanine, glutamine and glutamate.
\end{abstract}

Key Words ketosis, serum free amino acids, hypoglycemia, gluconeogenesis

In spite of the prevalence of episodic ketosis, recent investigation of this disorder in children has focused on ketotic hypoglycemia (1-13). Ketotic children with hypoglycemia are, however, far fewer than those without hypoglycemia. The present study must provide a clue to the elucidation of etiology of episodic ketosis without hypoglycemia.

Three hypothetical causes of ketotic hypoglycemia are: (1) Deficiency of glycogen in the liver $(1,4,13)$, (2) Inadequate production of alanine by the muscles, leading to secondary failure of hepatic gluconeogenesis $(2,6-9,12)$, and (3) Inadequate epinephrine production $(4,5)$. Of these, the second mechanism was supported by Pagliara et al., and gained numerous advocates.

The present paper aims to clarify the actual cause of episodic ketosis without

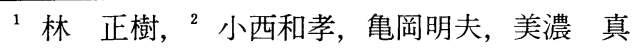


hypoglycemia. We believe that the second mechanism is applied to the development of this non-hypoglycemic disorder as well as to that of ketotic hypoglycemia.

\section{SUBJECTS AND METHODS}

The subjects consisted of 17 children between 2 and 11 years of age, 9 boys and 8 girls, having a history of cyclic vomiting associated with ketosis but without hypoglycemia. Between episodes they were perfectly well and showed no metabolic abnormalities on preliminary tests for oral glucose, glucagon or tolbutamide tolerance. The levels of fasting blood glucose, free fatty acids (FFA), and triglycerides examined during the 7 days prior to the trial were within normal ranges, while they were given the standard hospital diet.

The ketogenic provocative test was conducted by the method of Colle and Ulstrom(1). After an overnight fast, during which only water was allowed, the children were given a diet designed to provide $1,200 \mathrm{kcal}$ daily per $1.73 \mathrm{~m}^{2}$ of body surface area and consisting of $67 \%$ fat, $16 \%$ carbohydrate, and $17 \%$ protein. The diet was given in three equally divided portions at 8:00 a.m., 12:00 noon, and at 5:00 p.m.

Blood and urine specimens were collected at $0,4,8,12,16,20$, and $24 \mathrm{hr}$.

Blood was examined for glucose in terms of glucose oxidase with a Beckman Glucose Analyzer. The first $(0 \mathrm{hr})$ and last specimens were examined for serum amino acids with an amino acid analyzer (Japan Spectroscopic Co., Ltd. an JOEL JLC 6AH model). Urine was examined only for ketone body with Ketostix (Ames, Inc.).

\section{RESULTS AND DISCUSSION}

The results are given in Table 1 . All the 17 children developed ketonuria 12 and $16 \mathrm{hr}$ after beginning the ketogenic provocative test: none of them was hypoglycemic. Five children were hypoglycemic (blood glucose: less than $40 \mathrm{mg} / \mathrm{dl}$ ) on subsequent check-ups. All three children with clinical manifestations of pallor, lassitude, drowsiness and vomiting, which appeared to coincide with the development of ketosis, were among these five hypoglycemics. None developed convulsions due to hypoglycemia. No predilection for sex or age was detected.

This finding agrees with a number of recent views (10-14) in that test results alone draw no sharp line between normal children and children with ketotic hypoglycemia, and that both ketotic hypoglycemia and cyclic vomiting syndrome fall in a single entity.

The children tested were divided into two groups of hypoglycemic ( 5 children) and non-hypoglycemic (12 children). Figure 1 analyzes them for constituent free amino acids. The amino acids assayed were classified into two major groups of branched- and nonbranched-chain compounds according to their metabolic pathways of behavioral patterns, since nonbranched-chain amino acids, comprising 


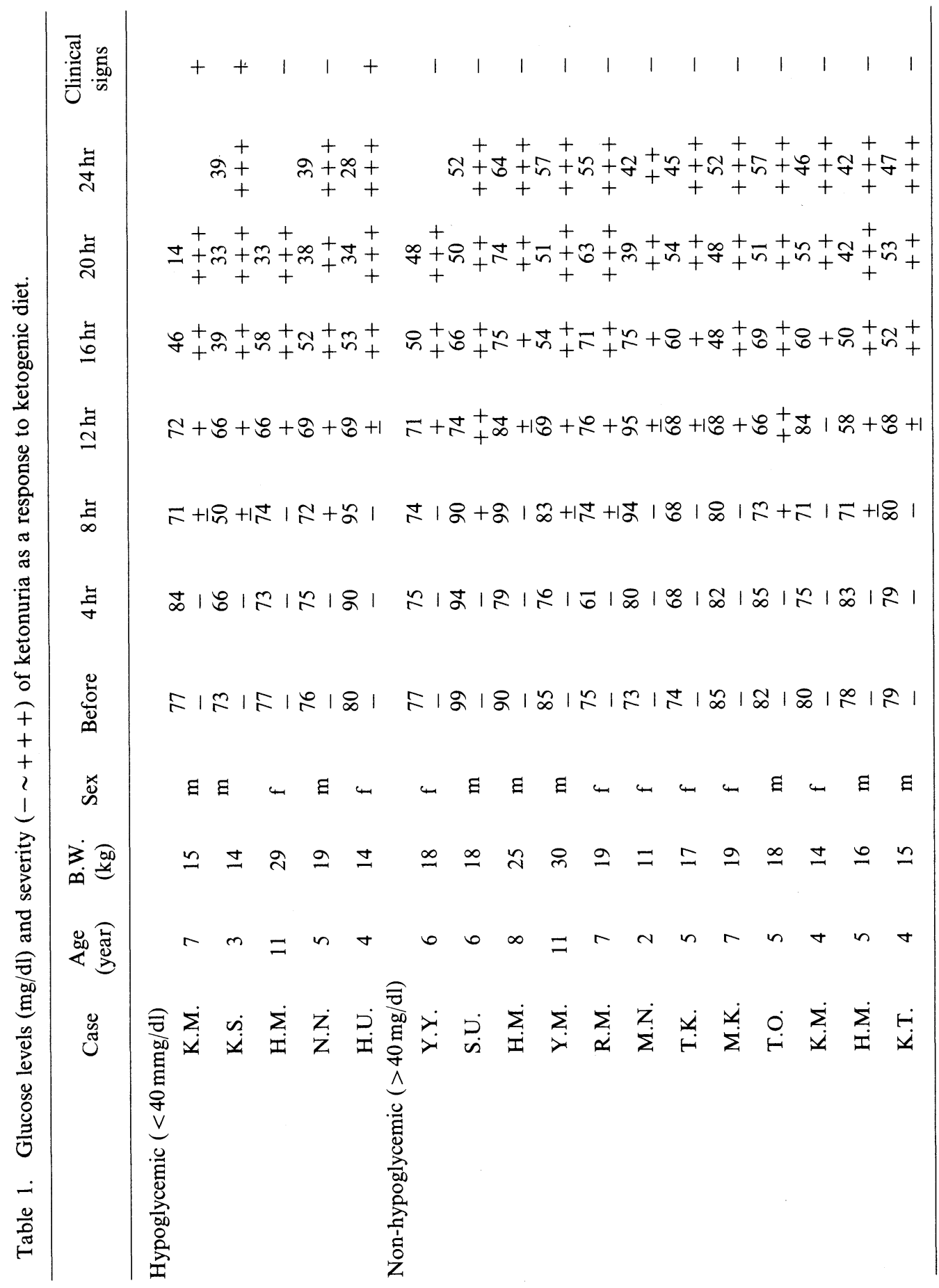

Vol. 27, No. 5, 1981 


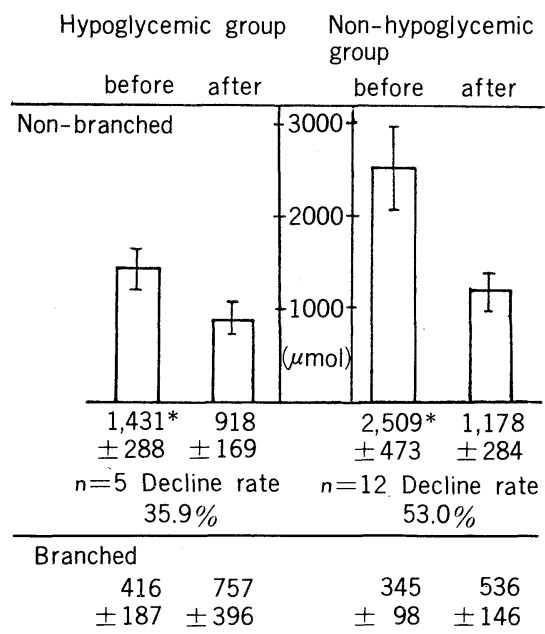

Fig. 1. Comparison of the total serum gluconeogenic amino acid levels before and after ketogenic diet. Data presented as Mean \pm SD. *Significant difference in mean value between hypoglycemic and non-hypoglycemic groups $(p<0.01)$.

aspartate, threonine, serine, proline, glycine, alanine, methionine, tyrosine, phenylalanine, glutamate and glutamine, by Haymond et al. (8), have been shown to be potentially gluconeogenic. As this figure shows, the serum level of the sum of gluconeogenic amino acids in hypoglycemic children before the ketogenic provocative test was far lower than that in non-hypoglycemic children, but nearly equal between the two groups after completion of the test. In other words, the decrement of gluconeogenic amino acids in the hypoglycemic group during the test was far greater in the non-hypoglycemic group.

Pagliara et al. (7-9) proposed that ketotic hypoglycemia involves depression of serum alanine-derived gluconeogenesis during energy deprivation. The present data on changes in serum alanine agreed essentially with their concept. The extremely low levels of serum gluconeogenic amino acids may be a cause of both ketosis and ketotic hypoglycemia in children.

The role of alanine deficiency, among other gluconeogenic amino acids, in hte development of children's hypoglycemia and ketosis has repeatedly been emphasized by Pagliara whose concept was based on experimental evidence from two independent investigators, Cahill (15) and Exton et al.(16). Transhepatic catheterization study in humans by Cahill indicated that in excess of $50 \%$ of glucose derived from gluconeogenic amino acids is formed from alanine. Exton et al., in their in vitro perfusion study, showed clearly that decreased delivery of alanine might be a rate-limiting event for gluconeogenesis.

Table 2 shows the serum levels of individual amino acids in our study. Markedly reduced amino acids were not only alanine, but included glutamine, glutamate and glycine. Branched-chain amino acids contrarily increased after the test. This finding convinced us that glutamine, glutamate and glycine, which have 
Table 2. Mean serum levels of amino acids in hypoglycemic and non-hypoglycemic children before and after ketogenic diet.

\begin{tabular}{|c|c|c|c|c|}
\hline \multirow{2}{*}{ Amino acids } & \multicolumn{2}{|c|}{ Hypoglycemic group } & \multicolumn{2}{|c|}{ Non-hypoglycemic group } \\
\hline & Before test & After test & Before test & After test \\
\hline Non-branched & \multicolumn{4}{|c|}{$(\mu \mathrm{mol} /$ liter $)$} \\
\hline Asp & $81.6 \pm 14.4$ & $43.3 \pm 10.6$ & $58.3 \pm 15.4$ & $37.5 \pm 12.6$ \\
\hline $\left.\begin{array}{l}\text { Thr } \\
\text { Ser }\end{array}\right\}$ & $222.0 \pm 42.2$ & $140.7 \pm 33.2$ & $342.5 \pm 54.1$ & $146.6 \pm 31.6$ \\
\hline Pro & $70.6 \pm 10.5$ & $53.3 \pm 7.8$ & $133.3 \pm 20.6$ & $80.0 \pm 12.5$ \\
\hline Gly & $256.4 \pm 59.2^{*}$ & $147.6 \pm 27.8$ & $436.6 \pm 101.2^{*}$ & $166.6 \pm 55.0$ \\
\hline Ala & $211.2 \pm 41.9 *$ & $163.6 \pm 23.8$ & $492.0 \pm 93.2^{*}$ & $233.3 \pm 38.6$ \\
\hline Met & $31.7 \pm 6.3$ & $25.5 \pm 6.0$ & $36.6 \pm 12.9$ & $27.5 \pm 7.0$ \\
\hline Tyr & $71.2 \pm 11.5$ & $62.0 \pm 14.6$ & $100.0 \pm 31.4$ & $57.5 \pm 11.3$ \\
\hline Arg & $92.3 \pm 15.6$ & $55.8 \pm 10.5$ & $99.2 \pm 24.2$ & $69.2 \pm 21.4$ \\
\hline $\left.\begin{array}{l}\text { Glu } \\
\text { Gln }\end{array}\right\}$ & $394.6 \pm 89.9^{*}$ & $226.4 \pm 39.0$ & $810.0 \pm 122.6^{*}$ & $369.2 \pm 97.6$ \\
\hline \multicolumn{5}{|l|}{ Branched } \\
\hline Val & $175.6 \pm 94.5$ & $318.4 \pm 223.4$ & $114.7 \pm 31.7$ & $165.0 \pm 42.5$ \\
\hline Ileu & $92.4 \pm 24.6$ & $170.4 \pm 72.1$ & $51.6 \pm 17.4$ & $135.8 \pm 47.9$ \\
\hline Leu & $148.2 \pm 67.4$ & $268.2 \pm 100.8$ & $178.3 \pm 48.2$ & $238.3 \pm 54.9$ \\
\hline
\end{tabular}

* Significant difference between hypoglycemic and non-hypoglycemic group $(p<0.01)$.

been assigned to an unduly low position from the gluconeogenic standpoint, actually prevent ketosis and hypoglycemia. Increased elevation of branched-chain amino acids, which coincided with decreases in nonbranched-chain amino acids, has been accounted for by increased protein catabolism and/or accumulation due to decreased transformation in the liver (17).

\section{REFERENCES}

1) Colle, E., and Ulstrom, A. (1964): Ketotic hypoglycemia. J. Pediatr., 64, 632-651.

2) Senior, B., and Loridan, L. (1969): Gluconeogenesis and insulin in the ketotic variety of childhood hypoglycemia and in control children. J. Pediatr., 74, 529-539.

3) Loridan, L., and Senior, B. (1970): Effect of infusion of ketones in children with ketotic hypoglycemia. J. Pediatr., 76, 69-74.

4) Rosenbloom, A. L., and Tiwary, C. M. (1972): Ketotic (idiopathic glucagon unresponsive) hypoglycemia. Arch. Dis. Child., 47, 924-926.

5) Court, J. M., Dunlop, M. E., and Boulton, T. J. (1974): Effect of epinephrine in ketotic hypoglycemia. Arch. Dis. Child., 49, 63-65.

6) Christensen, N. J. (1974): Hypoadrenalinemia during insulin hypoglycemia in children with ketotic hypoglycemia. J. Clin. Endocrinol. Metab., 38, 107-112.

7) Pagliara, A. S., Karl, I. E., DeVivo, D. C., Feigen, R. D., and Kipinis, D. M. (1972): Hypoalaninemia: a concomitant of ketotic hypoglycemia. J. Clin. Invest., 51, $1440-1449$. 
8) Haymond, M. W., Karl, I. E., and Pagliara, A. S. (1974): Ketotic hypoglycemia: an amino acid substrate limited disorder. J. Clin. Endocrinol. Metab., 38, 521-530.

9) Pagliara, A. S., Karl, I. E., Haymond, M. W., and Kipinis, D. M. (1973): Hypoglycemia in infancy and childhood. Part I. J. Pediatr., 82, 365-379.

10) Chaussain, J. L. (1973): Glycemic response to 24 hour fast in normal children and children with ketotic hypoglycemia. $J$. Pediatr., 82, 438-443.

11) Chaussain, J. L., Georges, P., Olive, G., and Job, J. C. (1974): Glycemic response to $24-$ hour fast in normal children and children with ketotic hypoglycemia: II. Hormonal and metabolic changes. J. Pediatr., 85, 776-781.

12) Chaussain, J. L., Georges, P., Calzada, L., and Job, J. C. (1977): Glycemic response to 24-hour fast in normal children. III. Influence of age. J. Pediatr., 91, 711-714.

13) Habbick, B. F., Meneish, A. S., and Stephanson, J. B. P. (1971): Diagnosis of ketotic hypoglycemia of childhood. Arch. Dis. Child., 46, 295-300.

14) Hayashi, M.: Studies on ketotic response with hypoglycemia in childhood. J. Osaka City Med. Cent., 24, 571-588.

15) Cahill, G. F. (1970): Starvation in man. New Engl. J. Med., 282, 668-675.

16) Exton, J. H., Mallette, L. E., Jefferson, L. S., Wong, E. H. A., Friedman, N., Miller, T. B., Jr., and Park, C. R. (1970): The hormonal control of hepatic gluconeogenesis. Recent Prog. Horm. Res., 26, 411-461.

17) Adibi, S. A. (1968): Influence of dietary deprivation on plasma concentration of free amino acids of man. J. Appl. Physiol., 25, 52-57. 